\title{
Analysis of Cascaded Three-Level Inverter based Multilevel STATCOM in High Power Applications
}

\author{
Amit Kadani ${ }^{1}$, Gopalaiah ${ }^{2}$ \\ ${ }^{1} \mathrm{M}$ Tech Student, Dept. of E\&IE, Dayananda Sagar College of Engineering, Bengaluru, \\ ${ }^{2}$ Professor, Dept. of E\&IE, Dayananda Sagar College of Engineering, Bengaluru
}

\begin{abstract}
In this paper a static var compensating scheme is using a cascaded three level inverter based multilevel inverter is proposed. This consist of two three level inverters connected in series through open end windings of a three phase transformer. To envisage the performance of the proposed system under balanced and unbalanced conditions the simulation is carried out in Matlab/Simulink.
\end{abstract}

Keywords: STATCOM, Three level inverter

\section{Introduction}

Static Compensator is a application of the flexible ac transmission system controllers. A Static var Compensator is a set of electrical devices for providing fast acting reactive power on high voltage electrical transmission networks. This device uses to compensate the reactive power, oscillation damping of the active power, flicker attenuation, and alsovoltage regulation, etc.

The voltage source inverters produce an output voltage or a current with levels either 0 or $\pm \mathrm{v}$ dc. They are known as the three level inverter. This output is not a sinusoidal wave. To obtain near sinusoidal wave using multilevel inverter.

The multilevel inverters have drawn tremendous interest in the power industry they present a new set of features that are well suited for use in reactive power compensation it may be easier to produce a high power ,high voltage inverter with the multilevel structure because of the way in which device voltage stresses are controlled in the structure increasing the number of voltage levels in the power rating the in the unique structure of multilevel voltage source inverters allows them to reach high voltages with low harmonics without the use of transformers or series connected synchronized switching device. As the number of voltage levels increases the harmonics content of the output voltage waveform decreases significantly.

In this paper, a static var emolument scheme is using for a cascaded three level inverter predicted multilevel inverter. The proposed system uses standard three level inverters for the multilevel operation. These inverters consist of large number of the dc sources, which are normally uses capacitors, to maintain these capacitors the converters will draw small amount of the active power. Then too due to mismatch in the in the process of conduction and due to switching losses the capacitors voltages will be unbalanced. Balancing these capacitor voltages is a big challenge in these inverter levels. To compensate this problem there are many topologies are available, among all those conventional methods, the proposed method is very effective, because the proposed method uses less number of capacitors in the circuit, hence the complexity of the circuit can be reduced.

\section{Cascaded Three-Level Inverter Design}

Fig 1 shows the Three level inverter circuit diagram it is connected to the control box which controls the whole circuit. IGBT's are used here as switching circuits, Multilevel Inverters have the advantage of reducing the voltage step changes, and hence the size and the cost of the main filter inductor for given current ripple, at the expense of increased complexity and cost of the power electronics and control components From this three level inverter we are drawing three phase voltage and currents through that we can measure the real and reactive power of the source.

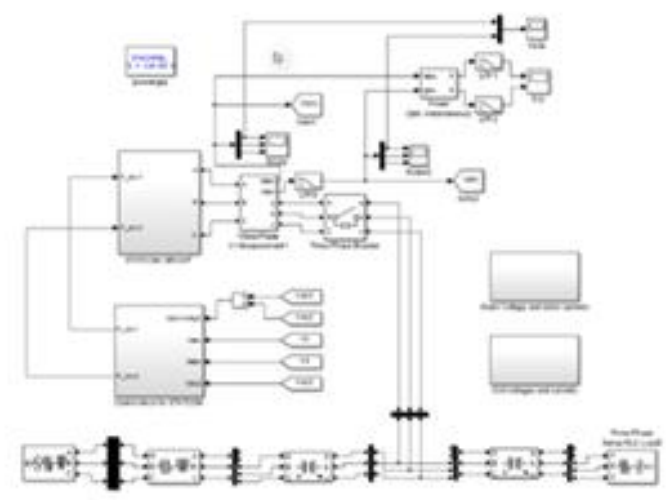

Figure 1: Simulation Circuit of three level cascaded Inverter

\section{STATCOM}

STATCOM (Static synchronous Compensator) is a electronics device using devices like IGBT, GTO. To regulate the reactive power flow through power network and increasing the stability power network. A Static synchronous Compensator is also known as Stativ synchronous Condenser (STATCON). The STATCOM is a member of Flexible AC Transmission System (FACTS) Family.

\section{Application of STATCOM}

Voltage stability is one of the most sizably voluminous quandaries in power systems. Engineers and researchers are endeavoring to consolidate a definition regarding to voltage stability, besides proposing techniques and methodologies for their analysis. Most of these techniques are predicated on the search of the point in which the system's Jacobian becomes singular, this point is referred as the point of 


\section{International Journal of Science and Research (IJSR) \\ ISSN (Online): 2319-7064}

Index Copernicus Value (2015): 78.96 | Impact Factor (2015): 6.391

voltage collapse or maximum load competency point. The series and shunt emolument are able to increment the maximum transfer capabilities of puissance network .Concerning to voltage stability, such emolument has the purport of injecting reactive power to maintain the voltage magnitude in the nodes proximate to the nominal values, besides, to reduce line currents and consequently the total system losses. Today due the development in the puissance electronics contrivances, the voltage magnitude in some node of the system can be adjusted through sophisticated and multifarious contrivances designated FACTS. One of them is the static synchronous compensator (STATCOM).

\section{Three Level Inverter Based Multilevel STATCOM}

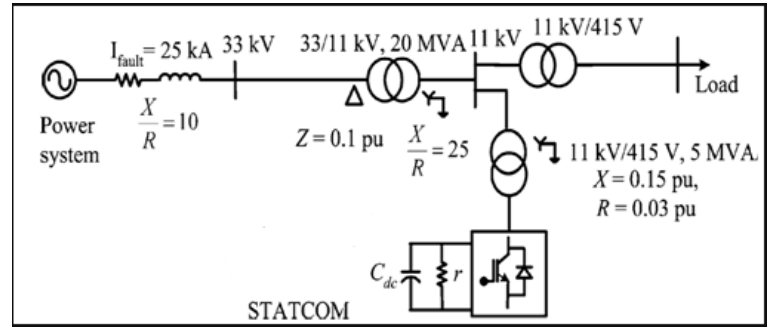

Figure 2: Power System Connected to STATCOM

The above fig 2 shows the Power system which connected to the proposed STATCOM model, through the power system input here $\mathrm{n}$ this circuit introducing a ground fault to check the performance of the system in Balanced and the Unbalanced modes.

And the fig 3 represents the System circuit diagram by considering This figure, both the inverters are connected in series and those are connected to the lower end of the transformer. And other side higher end of the transformer is connected to the Grid. To achieve the required objective the dc link voltages are maintained constant.

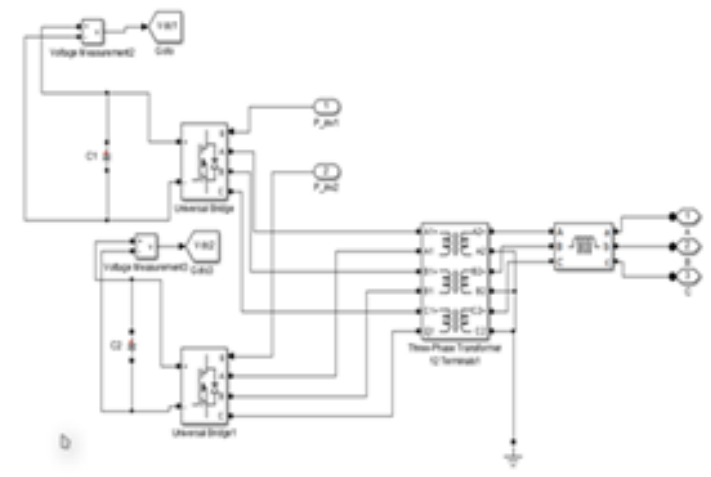

Figure 3: STATCOM circuit model

\section{Software Implements}

\section{- Introduction to MATLAB}

SimPowerSystems and SimMechanics of the Physical Modeling product family work together with Simulink to model electrical, mechanical and control systems.

\section{- Designing a Electrical Circuit with Powerlib Library}

The graphical user interface makes use of the Simulink functionality to interconnect various electrical components.
The electrical components are grouped in a special library called powerlib.

SimPowerSystems library is opened by entering the following command at the MATLAB prompt.

"Powerlib"

This command displays a Simulink window

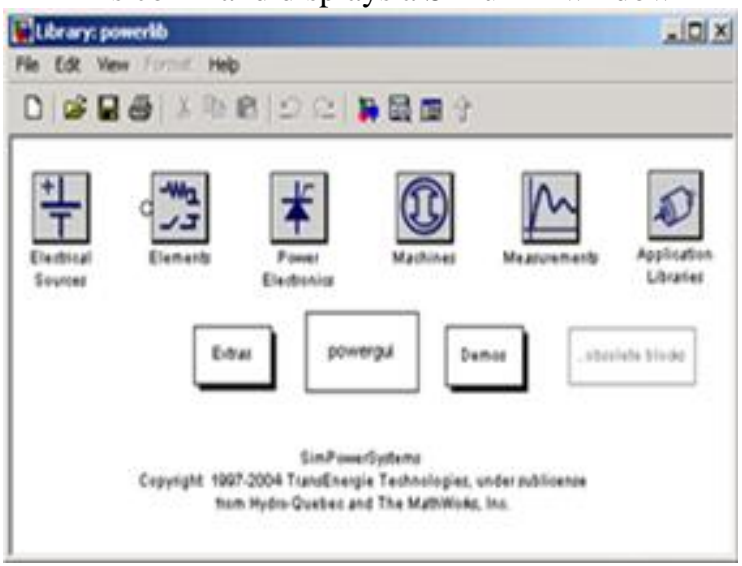

Figure 4: Powerlib Library in sumulink window

It is possible to open these libraries to produce the windows containing the blocks to be copied into given circuit. Each component is represented by a special icon having one or several inputs and outputs corresponding to the different terminals of the component.

\section{- Interfacing Electrical Circuit with Simulink}

The Voltage Measurement block acts as an interface between the Sim Power Systems blocks and the Simulink blocks. The Voltage Measurement block converts the measured voltages into Simulink signals. The Current Measurement block from the Measurements library of powerlib can also be used to convert any measured current into a Simulink signal.

It is also possible to interface from Simulink blocks to the electrical system. For example, it is possible to use the Controlled Voltage Source block to inject a voltage in an electrical circuit

\section{Applications of Inverter}

- Inverter is an electronic circuit which converts direct current (DC) to the alternating current (AC). Inverters can be used in many fields/ applications, like from small switching power supplies in computers to large electric applications that will transfer bulk power.

- The inverter is names so because it performs the opposite function of the rectifier. The inverter is utilized for emergency backup power in a habitation. The inverter is utilized in some aircraft systems to convert a portion of the aircraft DC power to AC. The AC power is utilized mainly for electrical contrivances like lights, radar, radio, motor, and other contrivances. 


\section{International Journal of Science and Research (IJSR) \\ ISSN (Online): 2319-7064}

Index Copernicus Value (2015): 78.96 | Impact Factor (2015): 6.391

Parameters Used in Design of System

Table 1: System Parameters

\begin{tabular}{|l|l|}
\hline Rated power & $5 \mathrm{MVA}$ \\
\hline Transformer voltage rating & $11 \mathrm{kV} / 400$ \\
\hline AC supply frequency, $\mathrm{f}$ & $50 \mathrm{~Hz}$ \\
\hline Inverter-1 dc link voltage, $\mathrm{V}_{\mathrm{dc}}$ & $659 \mathrm{~V}$ \\
\hline Inverter-1 dc link voltage, $\mathrm{V}_{\mathrm{dc} 2}$ & $241 \mathrm{~V}$ \\
\hline Transformer leakage reactance, $\mathrm{X}_{1}$ & $15 \%$ \\
\hline Transformer resistance, $\mathrm{R}$ & $3 \%$ \\
\hline DC link capacitance, $\mathrm{C}_{1}, \mathrm{C}_{2}$ & $50 \mathrm{mF}$ \\
\hline Switching frequency & $1200 \mathrm{~Hz}$ \\
\hline
\end{tabular}

\section{Results and Discussion}

The system shown in fig 1. Consider for the simulation and here simulation is carried out using MATLAB/Simulink.

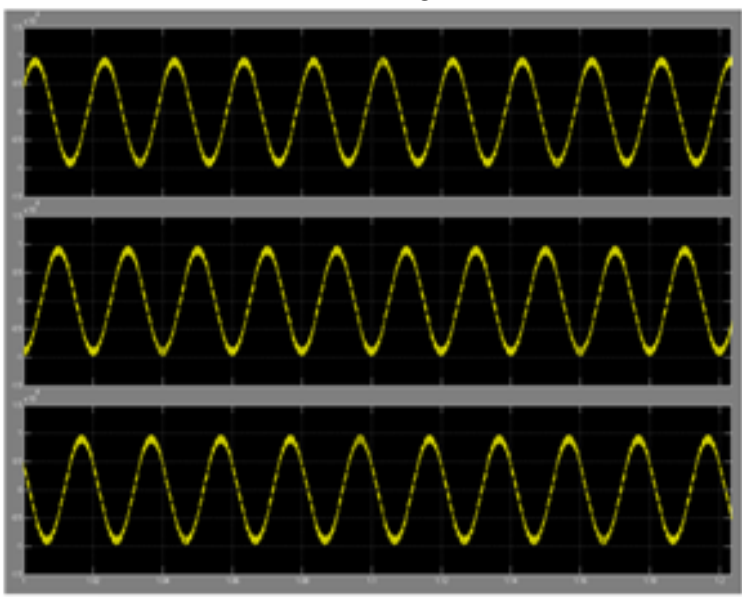

Fig 5. Three phase Voltages

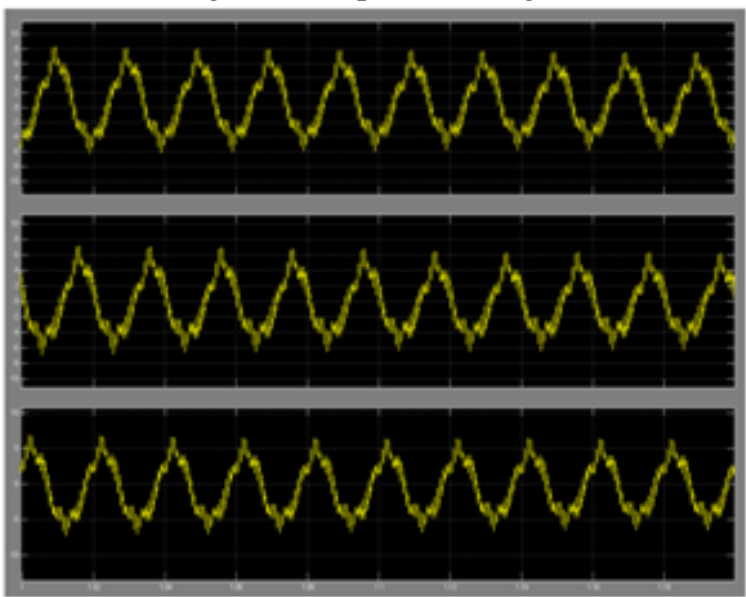

Figure 8: Three phase STATCOM currents

By considering the fig 5, it shows the graph of three phase line voltage Vs time, and fig 6 . Shows the graph of three phase current Vs time. From both above figures it can be observe that the inverter dc-link voltages are controlled at the irrespective values when the STATCOM mode turns to inductive mode form capacitive mode. Moreover, the dc-link voltage of inverter 2 attains its reference value faster compared to that of inverter 1 .

The voltage, current and power cognation formula is, $\mathrm{P}=$ VI. In an Alternating Current (AC) circuit when impedance element is considered to be pristine resistance, the current is in phase to the voltage. But when the impedance element consists of both reactance as well as resistance, the current is not in phase to the voltage. Thus the resoluteness of puissance becomes intricate. Here the product VI is more preponderant minuscule than the authentic potency. The excess power is verbalized to be reactive potency, which represents the energy supplemental relinquished by capacitors and/or inductors. The total power is given by the sum of the authentic and reactive potency. It is withal kenned as ostensible potency. The ratio of authentic power to total power is kenned as power factor. The potency factor is mathematically given as $\mathrm{kW} / \mathrm{kVA}$. So, in order to achieve unity power factor, reactive power should be mitigated utilizing some mitigating contrivances.

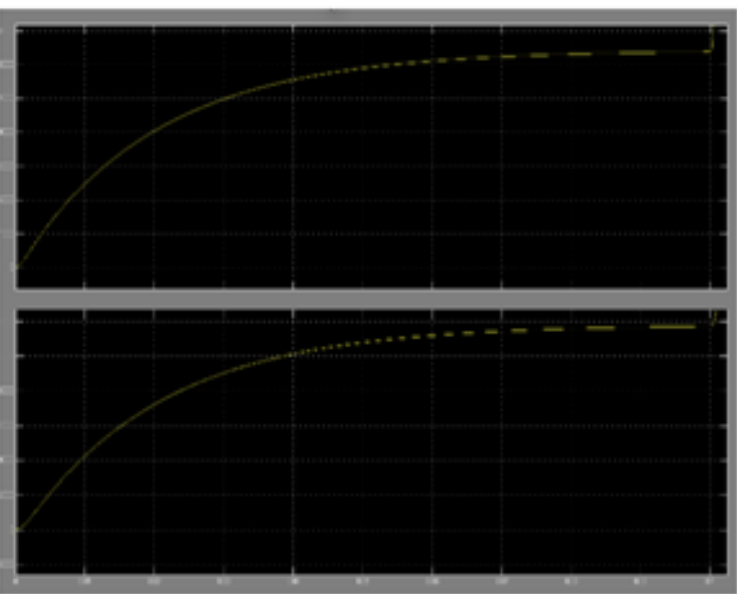

Figure 7: Power without STATCOM

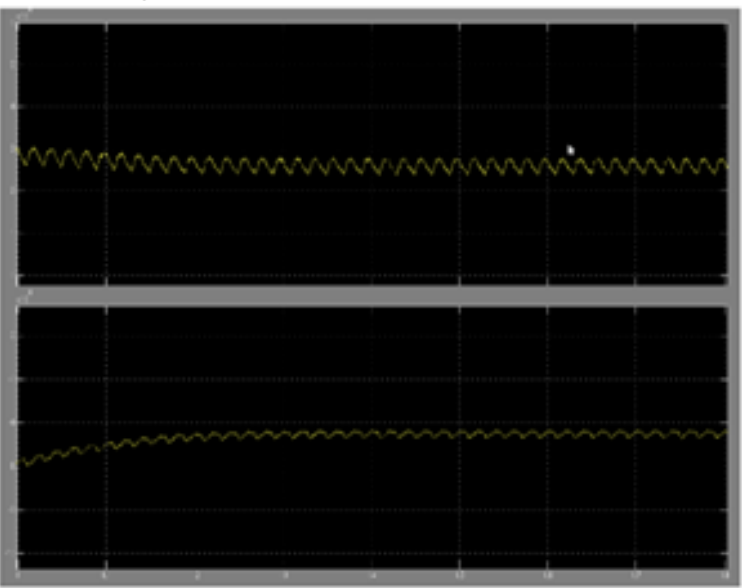

Figure 8: Power with STATCOM

Fig $7 \& 8$ Shows the power of the system with and without STATCOM. When we measure the power without connecting to the STATCOM the output result will not be in stable as shown in Fig 7. And if we measured the power by connecting the circuit to the STATCOM model then we can get the stable output as shown in fig 8 .

\section{Conclusions}

In this paper a cascaded three level inverter based multilevel inverter is compensated by the simple var scheme, the major issue is to balance the dc link inverter by using this scheme this can be overcome easily. The performance of the scheme is validated under the balanced and unbalanced condition of the voltages. Further, the cause for instability when there is a change in reference current is investigated. The dynamic

\section{Volume 6 Issue 7, July 2017 www.ijsr.net}




\section{International Journal of Science and Research (IJSR) \\ ISSN (Online): 2319-7064}

Index Copernicus Value (2015): 78.96 | Impact Factor (2015): 6.391

model is developed and transfer functions are derived. System behavior is analyzed for various operating conditions.

\section{References}

[1] N. G. Hingorani and L. Gyugyi, Understanding FACTS. Delhi, India: IEEE, 2001, Standard publishers distributors.

[2] B. Singh, R. Saha, A. Chandra, and K. Al-Haddad, "Static synchronous compensators (STATCOM): A review," IET Power Electron., vol. 2, no. 4, pp. 297-324, 2009

[3] H. Akagi, S. Inoue, and T. Yoshii, "Control and performance of a transformer less cascaded PWM STATCOM with star configuration," IEEE Trans. Ind. Appl., vol. 43, no. 4, pp. 1041-1049, Jul./Aug. 2007.

[4] H. Akagi, H. Fujita, S. Yonetani, and Y. Kondo, "A 6.6$\mathrm{kV}$ transformer less STATCOM based on a five-level diode-clamped PWM converter: System design and experimentation of a $200-\mathrm{V} 10-\mathrm{kVA}$ laboratory model," IEEE Trans. Ind. Appl., vol. 44, no. 2, pp. 672-680, Mar./Apr. 2008.

[5] A. Shukla, A. Ghosh, and A. Joshi, "Hysteresis current control operation of flying capacitor multilevel inverter and its application in shunt compensation of distribution systems," IEEE Trans. Power Del., vol. 22, no. 1, pp. 396-405, Jan. 2007.

[6] Y. Liu, A. Q. Huang, W. Song, S. Bhattacharya, and G. Tan, "Small signal model-based control strategy for balancing individual dc capacitor voltages in cascade multilevel inverter-based STATCOM," IEEE Trans. Ind. Electron., vol. 56, no. 6, pp. 2259-2269, Jun. 2009.

[7] E. G. Shivakumar, K. Gopakumar, S. K. Sinha, A. Pittet, and V. T. Rangathan, "Space vector PWM control of dual inverter fed open-End winding induction motor drive," in Proc. IEEE APEC, pp. 399-405, 2001.

[8] Mohaptra, K. Gopakumar and V. T. Somasekhar, "A harmonic elimination and suppression scheme for an open-end winding induction motor drive," IEEE Trans. Industrial Electron., vol. 50, No. 6, pp. 1187-1198, December 2003. 